Pregelj, Z. (2011) Sergei Yutkevich: Othello - Отелло (1955) [Электронный ресурс]// Russian Film. March 1. URL: http://russianfilm.blogspot.ru/2011/03/sergei-yutkevich-otello-1955-17.html (дата обращения: 14.09.2018).

Tatspaugh, P. (2007) The tragedies of love on film // The Cambridge companion to Shakespeare on film / ed. by R. Jackson. 2nd edn. Cambridge : Cambridge University Press. xii, 349 p. P. 141-164.

Weiler, A. H. (1960) Screen: Russian version of 'Othello': Shakespeare adaptation opens at the 55th St. English Voices used for showing here [Электронный pecypc]// The New York Times. May 16. URL: http://nytimes.com/movie/review?res=9A04E7DB153DE333A25755C1A9639C946191D6CF (дата обращения: 14.09.2018).

Welles, O., Bogdanovich, P. (1992) This is Orson Welles. N. Y. : HarperCollins. xxxv, 533 p.

Woll, J. (2000) Real images: Soviet cinemas and the Thaw. L. : Tauris. xvi, 267 p.

Yutkevich, S. (1957) MyWaywithShakespeare // Films and Filming. Vol. 4. No. 1. P. 8, 32.

Aата поступления: 25.09.2018 2.

Gaydin Boris Nikolaevich, Candidate of Philosophy, Head of the Research Department of Digital Technologies, Institute of Fundamental and Applied Studies, Moscow University for the Humanities; Associate Member, International Academy of Science (IAS, Innsbruck). Postal address: Bldg. 6, 5 Yunosti St., Moscow, Russian Federation, 111395. Tel.: +7 (499) 374-59-30. E-mail: bngaydin@ mosgu.ru

Гайдин Борис Николаевич - кандидат философских наук, начальник научно-исследовательского отдела цифровых технологий Института фундаментальных и прикладных исследований Московского гуманитарного университета, член-корреспондент Международной академии наук (IAS, Инсбрук). Адрес: 111395, Россия, г. Москва, ул. Юности, 5, корп. 6. Тел.: +7 (499) 374-59-30. Эл. aspec: bngaydin@mosgu.ru

DOI 10.17805/zpu.2018.4.21

\title{
Функция обращений к творчеству предшественников и младших современников Шекспира в романе Донны Тартт «Тайная история» $(1992)^{*}$
}

\author{
E. Н. ЧЕРНОЗёМОВА \\ МОСКОВСКИЙ ПЕДАГОГИЧЕСКИЙ ГОСУДАРСТВЕННЫЙ УНИВЕРСИТЕТ
}

В статье анализируется современный университетский роман американской писательницы Донны Тартт «Тайная история» (1992). Ее произведения неизменно интересны как массовому читателю, так и специалистам с университетским образованием, поскольку помимо увлекательного, детективно развивающегося сюжета в них отражается широкая

* Статья подготовлена в рамках проекта «Кристофер Марло и его творчество в русской и мировой культуре: междисциплинарный взгляд» при финансовой поддержке Российского фонда фундаментальных исследований (грант № 18-012-00679).

The article was prepared within the framework of the project "Christopher Marlowe and His Literary Heritage in Russian and World Culture: An Interdisciplinary Look" with financial support from the Russian Foundation for Basic Research (grant No. 18-012-00679). 
эрудиция автора, позволяющая ввести в произведение и увязать с его событиями факты культурной жизни отдаленных эпох. Эти переклички анализируются через изменяющиеся литературные предпочтения центрального персонажа романа, Ричарда Пайпена, по мере взросления его сознания. Университетская среда приводит провинциала от увлечения Эдгаром По к пониманию творчества Т. С. Элиота.

Основное внимание в статье уделено развертыванию смыслов, которые порой обозначаются автором романа одним лишь именем писателя-драматурга или весьма превратным толкованием Ричардом Пайпеном фактов биографии или творчества того или другого автора. При этом степень смыслового искажения может открыться только тому, кто знаком с материалом, который интерпретирует персонаж романа. Именно поэтому специальный акцент делается на отсылки автора романа к работам предшественников и младших современников Шекспира, в числе которых оказываются Кристофер Марло, Джон Уэбстер, Томас Мидлтон, Сирил Тернер и Джон Форд. Разбор литературно-художественных образов из произведений этих авторов вскрывает привносящие ими в художественную прозу дополнительные смыслы.

Текст доклада автора на Первой Всероссийской научной конференции «Кристофер Марло и его творчество в русской и мировой культуре: междисциплинарный взгляд», которая прошла в Москве 22-23 июня 2018 г.

Ключевые слова: современный университетский роман; К. Марло; У. Шекспир; современники Шекспира; американская литература; Донна Тартт; «Тайная история»

\section{ВВЕАЕНИЕ}

$\mathrm{T}$ ворчество Аонны Тартт - современной американской писательницы, отличающейся скрупулезностью работы над художественным текстом (она выпускает в свет не более одного романа в десятилетие), заслуженно отмечено вниманием читателей и критиков. Помимо ряда приемов, делающих ее творчество привлекательным Аля массового читателя, оно содержит материалы, чрезвычайно интересные для эрудитов разных специальностей. Рассмотрение перекличек сведений о литературе и искусстве отдаленных эпох с событийным рядом, лежащим на поверхности повествования, заслуживает исследовательского внимания и вскрывает дополнительные смыслы, актуализирующиеся при сопоставлении разных пластов текста.

Произведение Аонны Тартт «Тайная история» (The Secret History, 1992) сочетает черты университетского, детективного и психологического романа (Тартт, 2008). Первоначально оно имело название «Бог иллюзий», о чем говорит сама писательница в одном из аудиоинтервью Naughtie, J. (2014), и на это обстоятельство имеются ссылки не в одном книжном обзоре (Whitehouse, 2008; Lodge, 2004). Такое название имело основание, поскольку роман Тартт исследует, как именно влияют университетское образование, художественные тексты на формирование личности, как их открытия осваиваются студентами, как функция художественного произведения прояснять неясное, переводя его в светлый план сознания, порой приводит к обратному эффекту, способствует эскапизму, уходу от необходимости решать сложные проблемы. Присутствие многих литературных ассоциаций в романе оправдано, поскольку основное действие связано с университетским колледжем гуманитарной направленности в городке Хэмпдене штата Вермонт. Колледж основан в 1895 г., а персонажами романа являются студенты, изучающие искусство, язык и культуру Аревней Греции.

Аля них самыми значимыми оказываются, конечно, материалы античной литературы и искусства. Изучению античного кода в романе посвящена статья О. Ю. Анцыферовой, в которой рассмотрены античные реминисценции, возникающие в тексте (Анцыферова, 2015: 22-27). Цель статьи - проанализировать функции античных образов в романе. Автор статьи обращает внимание на то, что Тартт часто описывает чита- 
тельские вкусы и предпочтения персонажей. По ним можно проследить становление гуманитарного сознания персонажей, их профессиональное взросление, рост уровня общей и гуманитарной культуры. Именно О. Ю. Анциферовой принадлежит и работа, целью которой является выявление жанровых особенностей университетского романа (Анцыферова, 2008: Электронный ресурс), в чем она идет за ранее проведенным исследованием А. М. Аюксембурга (Аюксембург, 1988).

\section{ИИТЕРАТУРНЫЕ ВКУСЫ ВЗРОСАЕЮЩЕГО СОЗНАНИЯ}

Повествование в произведении ведется от лица Ричарда Пайпена, приехавшего в колледж, спасаясь от деспотизма отца, из калифорнийского городка Плано, в котором «мало интересного, и уж совсем ничего радующего глаз» (ч. 1, гл. 1) (Tartt, 1992).

В его жизни на севере от Силиконовой долины в рядах типовых бунгало, автокинотеатрах среди источаемых асфальтом волн жара была единственная отдушина семинар по древнегреческому языку, начав изучение которого он находит интерес и проявляет способности. Став студентом колледжа, Ричард стремится продолжить изучение древнегреческого. Аитературные ассоциации Ричарда-студента в начале обучения в колледже связаны с достаточно популярными авторами и произведениями. Например, вынужденную необходимость долгого просиживания в кафе или в приемной поликлиники из-за невозможности вернуться в неотапливаемую снимаемую им дешевую каморку он сопрягает с обретением способности быть невидимым и вспоминает при этом человека-невидимку Уэллса, ведь его перестают замечать официантки и медсестры (Тартт, 2008). Все его физические силы уходили на борьбу с холодом, и его охватывали, как он признается, болезненные видения в духе Эдгара По (там же).

По мере взросления Ричарда его читательские предпочтения меняются. В конце года обучения в колледже летом он старается читать Пруста. А через много лет после окончания свои впечатления от жизни студенческого городка передает строками Т. С. Элиота.

Из-за трагических событий, участниками которых стали члены семинара по изучению древнегреческого языка, группа была расформирована, специализация закрыта. Студентам было предложено перейти на специальность английской филологии. Ричард, выбирая специализацию, останавливает выбор на эпохе короля Якова I, что, по его словам, многим казалось странным. Однако Ричарда это не смущало. Ему было необходимо разобраться в произошедшем, и лучшего материала, по его мнению, он найти не мог: «никто не мог сравниться с этими авторами в изображении катастрофы» (там же). Это признание выдает то, что Ричард воспринимает случившееся именно как катастрофу.

Вполне очевидно, что, осваивая творчество предшественников и младших современников Шекспира, Ричард стремится разобраться в той трагедии, участником которой он стал: «Я сидел над ними часами, размышлял, делал выписки и заметки. Никто не мог сравниться с моими авторами в изображении катастрофы. Они не только понимали, что такое зло, но и сознавали все многообразие уловок, при помощи которых оно прикидывается добром. Мне казалось, что они проникают в самую суть, что, говоря о пороках людей и перипетиях их судеб, они указывают на главное - невосполнимую ущербность всего мироустройства» (там же: 561). «Невосполнимая ущербность всего мироустройства», воспроизводимая мастерами слова, служит для Ричарда неким психологическим заслоном, путем к самооправданию. 


\section{РАСКРЫТИЕ СВЕРНУТЫХ СМЫСАОВ}

Эпизод, в котором переданы ассоциации жизненных впечатлений Ричарда с литературными произведениями предшественников и современников Шекспира, написан плотно, в несколько абзацев и содержит десяток имен и названий, каждое из которых соотносимо с событиями романа, пережитыми Ричардом.

Хронологически первым в ряду авторов, привлекших его внимание, стоит имя Кристофера Марло. Аонна Тартт заставляет своего персонажа, отдав должное творчеству выдающегося драматурга, отозваться о его личности, знакомясь с обстоятельствами жизни которой, Ричард убеждается в совместимости гениальности и злодейства, а именно в повторе того, что он наблюдал в образе жизни своего сокурсника Генри. Судьба Марло будто бы убеждает его в вечности, неединичности и неслучайности сочетания столь несочетаемых качеств: «Воспитанник Кембриджа, самый блестящий из “университетских умов”, друг Уолтера Роли и Томаса Нэша, Марло вращался в высоких литературных и политических кругах; <... И в то же время это был убийца, фальшивомонетчик, человек беспутных привычек и сомнительных знакомств, который “умер, бранясь” в таверне в возрасте двадцати девяти лет» (там же: 562).

Обращаясь к фактам, связанным с днем смерти Марло, автор заставляет Ричарда рассказать о том, что провел его драматург в обществе «трех человек, пользовавшихся очень дурной славой: один был мошенником, другой - агентом тайной полиции, третий - осведомителем и провокатором» (там же). В тексте романа нет прямых параллелей этих обстоятельств с теми, в которых погибли фермер, Банни, Генри, как нет и прямых параллелей рода занятий трех людей, сопричастных смерти Марло, с теми, кто были свидетелями каждой из трех смертей персонажей романа, но ассоциативные параллели, связанные с провокациями, тайным осведомительством, в которых сознаются персонажи романа и о которых умалчивают, в сознании читателя возникают.

Пережитое Ричардом странно меняет его сознание. В числе авторов, привлекших внимание Ричарда, названы Уэбстер и Мидлтон, Тернер и Форд. Притягательным для него оказывается страшное и жестокое: «...мне был по вкусу мир, в котором жили их персонажи: мир, освещенный не солнцем, а предательским пламенем свечей, мир, где невинность всегда оказывалась попранной, а злодеяние - ненаказанным» (там же: 561). В этом есть компенсаторная необходимость художественного проживания содеянного и оправдания безнаказанности участников убийства Банни, к которому имеет отношение и сам Ричард.

Плотно данный текст с перечислением имен и названий ( «Меня притягивали уже сами названия пьес, старомодные и возвышенно-броские: "Недовольный”, "Белый Аьявол”, “Разбитое сердце”...» (там же) соотносим по плотности ассоциаций с интеллектуальной поэзией Т. С. Элиота. Каждое из приведенных названий бросает отсвет на состояние Ричарда и его оценку своей роли в произошедшем. Но так же, как и произведения Т. С. Элиота, имена и названия в тексте Аонны Тартт обладают свернутостью и более информативны для университетски образованных читателей, знатоков искусства. Аля них Ажон Уэбстер - не только автор, считающийся многими критиками вторым после Шекспира по поэтическому таланту в английской драматургии XVII в. Он автор упоминаемого в тексте Аонны Тартт «Белого дьявола» (White Devil, между 1609 и 1612) и кровавых трагедий со страшными злодеяниями, плясками сумасшедших, ужасами, которые сводят с ума самих злодеев.

Такова «Герцогиня Амальфи» (The Duchess of Malfi, 1612-1613, публ. 1623) (Уэбстер, 1959; Черноземова, 1998a). Персонаж этой трагедии ученый-чудак Боссола, втя- 
нутый в злодеяния и старающийся многое исправить, выносит вердикт миру: «Один убийца вешает другого! / И это вы зовете правосудьем?» (Уэбстер, 1959: 240). Несчастен мир, в котором наградой доброму деянию является лишь оно само. Характеристика Боссолы в трагедии Уэбстера сродни учености Генри в романе Аонны Тартт: он занимается наукой из любви к науке, «он потратил немало времени, чтобы основательно изучить греческий и троянский военный строй, опираясь на Гомерову “ИлиаАу”» (т. 1, акт 3, сц. 3; Уэбстер, 1959: 206), он «из тех, которые занимаются наукой, чтобы установить, какой длины была палица Геркулеса, какого цвета была борода у Ахилла и страдал ли Гектор от зубной боли. Он чуть не погубил своего зрения, исследуя точное соотношение между размерами носа Цезаря и рожка для обуви» (там же). Но он же храбрейший человек, «во дворце / Единственный, пожалуй, обличитель» (акт 1, сц. 1; там же: 136), который сознает: «репутация мудреца - страшная штука; она способна задавить человека. Счастье заключается в простоте. Ведь тончайшее безумие происходит от тончайшей мудрости» (акт 11, сц. 1; там же: 160).

Примером размышлений о добре и зле, привлекаемых Роберта в творчестве указанных авторов, могут стать слова Боссолы:

доброта «должна бы

Июдские души делать благородней,

Меня же превращает в негодяя (...)

Так любит бес подслащивать грехи

И представлять нам сущим благородством,

Что небеса назвали бы злодейством»

(там же: 144-145; курсив наш. - E. Ч).

Хотя Боссола не говорит о «вывихнутости» своего века, совершенно очевидно, что ему кажется несправедливым существующее положение дел: «чем людей вознаграждают / За добрые дела? Аишь доброй славой. / А что за преступление их ждет? Высокий чин, и деньги, и почет» (там же: 145$)$. Он считает такую изломанность дьявольской, т. е. меняющей местами добро и зло.

Узнавание себя и своих проблем взаимоотношений с миром Ричард может находить и в следующих словах Боссолы: «В какой глубокой пропасти и тьме / Извечно человечество живет, / Трусливое, изнеженное, злое! / \ишь те, в ком бьются честные сердца, / Сражаются за правду до конца. / Я, к сожаленью, путь избрал иной!» (Акт 5, сц. 5; там же: 279).

Столь же созвучны размышлениям персонажа Аонны Тартт материалы произведений Томаса Мидлтона - автора сатирических комедий и трагедий мести. Показательны названия его сатирических комедий: «Безумный мир, господа» (A Mad World, My Masters, ок. 1604, публ. 1608) и «Как провести старика» (A Trick to Catch the Old-One, 1604-1607, публ. 1608). В финале его трагедии «Женщины, берегитесь женщин» (Women beware Women, между 1620 и 1627, публ. 1657) происходят убийства в ходе придворного представления: яд оказывается в кубке Ганимеда, в ароматических курениях и на вовсе не бутафорских стрелах Купидона. Эти события соотносятся с замыслами Генри отравить Банни, которыми он делится с Робертом.

Трагедия Т. Мидлтона «Оборотень» (The Changeling, 1622) разрабатывает мысль о недопустимости убийства по любым мотивам, что впрямую соотносится с уроками, которые преподносит Ричарду жизнь (Мидлтон, 1986: 119-188; Черноземова, 1998b). Аюбовь в пьесе оборачивается злодейством, стремление к счастью - смертью. 
Наибольший интерес для Ричарда должна представлять трагедия Ажона Форда «Разбитое сердце» (The Broken Heart, 1633), поскольку ее действие связано с изучаемой им Аревней Грецией и персонажи названы говорящими именами, смысл которых поймет только знающий греческий язык или читатель, обращающийся к комментариям (см.: Форд, 1986; Черноземова, 1998c). В ней действуют Профил (от греч. prophilos бывший друг), Оргил (от греч. orgylos - вспыльчивый) - сын спартанского архонта Кротолона (от греч. krotolon - треск, грохот), дочь царя Спарты, принцесса Каланта (от греч. kallon anthos - прекрасный цветок), предназначенная принцу Аргоса Неарху (от греч. nearchos - новый правитель), Фраз (от греч. phrasos - дерзкий, смелый), отец Пентеи (от греч. penteo - оплакиваю). Наблюдаемые Ричардом в жизни отношения близнецов - его сокурсников Чарльза и Камиллы - соотносимы с тем, как развиваются в трагедии отношения брата и сестры Итеокла и Пентеи, Оргила и Эфрании (от греч. eupbraino - радуюсь), имя которой противоположно по значению имени Пентеи и подчеркивает, что героини находятся в принципиально различной зависимости от братьев - одна подчинена своенравному и жестокосердному человеку, другая - имеющему представление о глубине душевных страданий. Есть в трагедии Ажона Форда и параллель с ученичеством и отношениями с учителем: пытаясь найти уединение и привести мысли в согласие, Оргил становится учеником в гимнасии философа Текникуса (от греч. tecknikos - умелый, мастерский). Со случившимся на глазах у Ричарда с Генри соотносится в трагедии Форда самоубийство Оргила, приговоренного к смерти за справедливую, с его точки зрения, месть за смерть сестры, которому разрешено самому выбрать вид казни.

Из всего многообразия сюжетов и характеров, позволяющих Ричарду размышлять над случившимся в его жизни, он выбирает творчество Сирила Тернера (Tourneur Cyril, 1575-1626), которому решает посвятить магистерскую диссертацию. С 1656 г. до конца XIX в. Тернеру приписывалась анонимная пьеса «Трагедия мстителя» (The Revenger`s Tragedy), первая известная публикация которой относится к 1607 г. С конца XIX в. кандидатом в авторы пьесы становится Мидлтон. В английских изданиях последних лет пьесу предпочитают публиковать как анонимную.

Финал «Трагедии мстителя» наталкивает на размышления о том, как мог бы и должен был бы поступить Ажулиан Морроу - руководитель семинара по древнегреческому языку в романе Аонны Тартт, узнав о том, что его подопечные убили однокурсника. Ажулиан без объяснений со студентами написал заявление об увольнении и исчез из их жизни, что расценивается одним из них как трусость и бегство: заяви он на них в полицию - это было бы поступком. Подопечные Ажулиана со ссылкой на якобы имеющийся отклик о нем Т. С. Элиота утверждают, что их уважаемый научный руководитель заботится только о своем покое и репутации. В проговариваемых ими мотивах его поступка нет и намека на его привязанность и любовь к воспитанникам, которую он не однажды проявлял. В финале «Трагедии мстителя» братья-мстители осуществляют убийство ве-

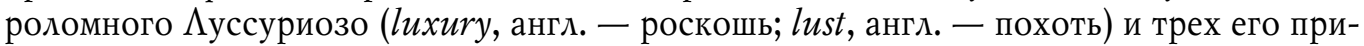
ближенных. Они провозглашают герцогом старика Антонио, чью жену обесчестил $\Lambda$ уссуриозо, и, выказывая ему полное доверие, сознаются в содеянном. Трагедия мстителей, отстаивающих честь своих близких, заключается в том, что братьев приговаривают к смерти, видя в их решимости и неукротимости будущую угрозу для нового правителя. Не меньшим трагизмом пропитано то, что вся жизнь мстителя оказывается отравленной, подчиненной необходимости мстить, и наполняется реалиями смерти (череп, яд, необходимость переодевать труп, вынашивать замысел и осуществлять убийство). 


\section{ЗАКАЮЧЕНИЕ}

Таким образом, компактный в несколько абзацев эпизод, наподненный именами авторов и названиями произведений, при развертывании заключенных в нем смыслов оказывается вплотную связанным с событиями романа и той оценкой, которую им дает автор повествования. Авторская оценка не совпадает с той, что дает им персонаж романа, трактующий факты биографии Марло и произведения младших современников Шекспира (Вебстера, Мидлтона, Тернера, Форда) превратно с целью оправдать случившееся и свою роль в произошедшем. Здесь уместно обратить внимание на утверждение Ф. Ницше: «...наличие опыта должно быть обязательным условием для филолога - но это значит: сперва будь человеком, тогда и в качестве филолога ты будешь небесплоден. Отсюда следует, что филологами пригодны быть зрелые мужи, те, кто на всем протяжении богатой опытом жизни филологами не были» (Ницше, 2001: Электронный ресурс). Развертывание закодированных смыслов - разбор литературно-художественных образов из произведений этих авторов - усиливает смысловые акценты, вскрывает дополнительные смыслы, которые неосведомленный читатель угадывает интуитивно. Это позволяет с неподдельным интересом знакомиться с содержанием романа как массовому читателю, так и любителям интеллектуальной прозы.

\section{СПИСОК АИТЕРАТУРЫ}

Анцыферова, О. Ю. (2008) Университетский роман: жизнь и законы жанра [Электронный pecypc]// Вопросы литературы. № 4. URL: http://magazines.russ.ru/voplit/2008/4/an13.html (аaта обращения 04.07. 2016).

Анцыферова, О. Ю. (2015) Античный код в университетском романе Аонны Тартт «Тайная история» // Вестник Нижегородского университета им. Н. И. Аобачевского. № 2 (2). С. $22-27$.

Һюксембург, А. М. (1988) Англо-американская университетская проза. История, эволюция, проблематика, типология. Ростов-на-Аону : Изд-во Ростовского гос. ун-та. 280 с.

Мидлтон, Т. (1986) Оборотень / пер. с англ. Г. М. Кружкова // Младшие современники Шекспира / отв. ред. А. Н. Горбунов. М. : МГУ. 592 с. С. 119-188.

Ницше, Ф. (2001) Мы, филологи. Отрывки из ненаписанной книги / сост. и пер. А. Россиуса [Электронный ресурс] // H $\Lambda$ О. №50. URL: http://magazines.russ.ru/nlo/2001/50/ni.html (дата обращения: 30.05 .2016$)$.

Тартт, А. (2008) Тайная история. Роман / пер. с англ. А. Бородкина, Н. Иенцман. М. : Иностранка. 704 с.

Уэбстер, Аж. (1959) Герцогиня Амальфи / пер. с англ. П. Мелковой // Современники Шекспира / отв. ред. А. Н. Горбунов. М. : МГУ. 592 с. Т. 1. С. 129-280.

ФорА, Аж. (1986) Разбитое сердце / пер. с англ. С. Э. Таска // Младшие современники Шекспира / отв. ред. А. Н. Горбунов. М. : МГУ. 592 с. С. 189-258.

Черноземова, Е. Н. (1998а) Герцогиня Амальфи // Энциклопедия литературных героев. Зарубежная литература: Возрождение. Барокко. Классицизм / под ред. И. О. Шайтанова. М. : Олимп ; АСТ. 766 с. С. $76-80$.

Черноземова, Е. Н. (1998b) Оборотень // Энциклопедия литературных героев. Зарубежная литература: Возрождение. Барокко. Классицизм / под ред. И. О. Шайтанова. М. : Олимп ; АСТ. 766 c. C. $251-252$.

Черноземова, Е. Н. (1998с) Разбитое сердце // Энциклопедия литературных героев. Зарубежная литература: Возрождение. Барокко. Классицизм / под ред. И. О. Шайтанова. М. : Олимп ; АСТ. 766 с. С. $480-481$.

Lodge, D. (2004) Exiles in a Small World [Электронный pecypc]// The Guardian. 8 мая. URL: http://books.guardian.co.uk/review/story/0,12084,1211200,00.html (дата обращения: 30.05.2016).

Naughtie, J. (2014) Bookclub. Donna Tartt's Secret History [Электронный ресурс]// BBC Radio 4. URL: https://www.bbc.co.uk/programmes/b03nrrbm (дата обращения: 30.05.2016). 
Tartt, D. (1992) The Secret History. N. Y. : Alfred Knopf, Inc. 523 p.

Whitehouse, L. (2008) Book of a Lifetime: The Secret History, by Donna Tartt [Электронный peсурс]// The Independent. Friday, January 11. URL: http://www.independent.co.uk/arts-entertainment/ books/reviews/book-of-a-lifetime-the-secret-history-bydonna-tartt-769505.html (дата обращения: 30.05.2016).

Aата поступления: 30.08 .2018 2.

\author{
THE FUNCTIONS OF REFERENCES TO THE SHAKESPEARE'S \\ PREDECESSORS AND YOUNGER CONTEMPORARIES WORKS \\ IN THE NOVEL BY DONNA TART «THE SECRET HISTORY» (1992) \\ E. N. CHERNOZEMOVA \\ Moscow State PeDAgogICAL UNIVERSITY
}

The article analyzes the modern University novel "Secret History" (1992) by the American writer Donna Tart. Her works are always interesting, as for a mass reader and so for professionals with a University education, because in addition to exciting and detective developing of the plot they reflect the great erudition of the author and allow to enter into the work and linked to its events the facts of the cultural life of remote eras. These echoes are analyzed through the changing literary preferences of the novel's central character, Richard Pipen, as his consciousness matures. The University environment brings a hick from the fascination with Edgar Allan Poe to the understanding of T. S. Eliot's works.

The main attention is paid to the development of meanings, which are sometimes designated by the author of the novel only by the name of the playwright or by a very wrong interpretation of the facts of their biography or creativity by Richard Papen. At the same time, the degree of semantic distortion can be revealed only to those who are familiar with the material that interprets the character of the novel. That is why special emphasis is placed on those references that make the author of the novel to the works of predecessors and younger contemporaries of Shakespeare, including Christopher Marlow, John Webster, Thomas Middleton, Cyril Turner and John Ford. The analysis of literary images from the works of these authors reveals additional meanings that they bring to the text of the novel.

The text of the author's report at the First all-Russian scientific conference "Christopher Marlow and his work in Russian and World culture: an interdisciplinary view", which was held in Moscow on June 22-23, 2018.

Key words: modern University novel; W. Shakespeare; Shakespeare's contemporaries; American literature; Donna Tartt; "Secret History"

\title{
REFERENCES
}

Antsyferova, O. Yu. (2008) Universitetskiy roman: zhizn i zakony zhanra. Voprosy literatury, no. 4 [online] Available at: http://magazines.russ.ru/voplit/2008/4/an13.html (access date 04.07. 2016). (In Russ.).

Antsyferova, O. Yu. (2015) Antichnyy kod v universitetskom romane Donny Tartt «Taynaya istoriya». Vestnik Nizhegorodskogo universiteta im. N. I. Lobachevskogo, no. 2 (2), pp. 22-27. (In Russ.).

Chernozemova, E. N. (1998a) Gertsoginya Amalfi. In: Entsiklopediya literaturnykb geroyev. Zarubezhnaya literatura: Vozrozhdeniye. Barokko. Klassitsizm / ed. by I. O. Shaytanov. Moscow, Olimp, AST. 766 p. Pp. 76-80. (In Russ.).

Chernozemova, E. N. (1998b) Oboroten. In: Entsiklopediya literaturnykb geroyev. Zarubezhnaya literatura: Vozrozhdeniye. Barokko. Klassitsizm / ed. by I. O. Shaytanov. Moscow, Olimp; AST. 766 p. Pp. 251-252. (In Russ.).

Chernozemova, E. N. (1998c) Razbitoye serdtse. In: Entsiklopediya literaturnykb geroyev. Zarubezhnaya literatura: Vozrozhdeniye. Barokko. Klassitsizm / ed. by I. O. Shaytanov. Moscow, Olimp, AST. 766 p. Pp. 480-481. (In Russ.). 
Ford, Dzh. (1986) Razbitoye serdtse / transl. from Engl. By S. E. Taska. In: Mladshiye sovremenniki Shekspira / ed. by A.N. Gorbunov. Moscow, MGU. 592 p. Pp. 189-258. (In Russ.).

Lodge, D. (2004) Exiles in a Small World. The Guardian, May 8 [online] Available at: http://books.guardian.co.uk/review/story/0.12084.1211200.00.html (access date: 30.05.2016). (In Russ.).

Lyuksemburg, A. M. (1988) Anglo-amerikanskaya universitetskaya proza. Istoriya evolyutsiya. problematika. tipologiya. Rostov-na-Donu, Izd. Rostovskogo gos. un-ta. 280 p. (In Russ.).

Midlton, T. (1986) Oboroten / transl. from Engl. by G. M. Kruzhkov. In: Mladshiye sovremenniki Shekspira / ed. by A. N. Gorbunov. Moscow, MGU. 592 p. Pp. 119-188. (In Russ.).

Nitsshe, F. (2001) My filologi Otryvki iz nenapisannoy knigi / comp. and transl. by A. Rossius. NLO, no. 50 [online] Available at: http://magazines.russ.ru/nlo/2001/50/ni.html (access date 30.05. 2016). (In Russ.).

Tartt, D. (2008) Taynaya istoriya. Roman / transl. from Engl. by D. Borodkin. Moscow, Inostranka. 704 p. (In Russ.).

Uebster, Dzh. (1959) Gertsoginya Amalfi / transl. from Engl. by P. Melkovoy. In: Sovremenniki Shekspira / ed. by A.N. Gorbunov. Moscow, MGU. Vol. 1.592 p. Pp. 129-280. (In Russ.).

Naughtie, J. (2014) Bookclub. Donna Tartt's Secret History. WS Radio 4 [online] Available at: https://www.bbc.co.uk/programmes/b03nrrbm (access date: 30.05.2016).

Tartt, D. (1992) The Secret History. New York, Alfred Knopf. Inc. 523 p.

Whitehouse. L. (2008) Book of a Lifetime: The Secret History. by Donna Tartt. The Independent, Friday. January 11 [online] Available at: http://www.independent.co.uk/arts-entertainment/ books/reviews/book-of-a-lifetime-the-secret-history-bydonna-tartt-769505.html (access date: 30.05.2016).

Submission date: 30.08 .2018 .

Чернозёмова Елена Николаевна - доктор филологических наук, профессор, профессор кафедры всемирной литературы Московского педагогического государственного университета, президент Российской ассоциации преподавателей английской литературы. Адрес: 119991, Россия, Москва, ул. Малая Пироговская, А. 1. Тел.: +7 (499) 246-57-12. Эл. адрес: chernozem888@yandex.ru

Chernozemova Elena Nicolaevna, Doctor of Philology, Professor, Professor of the Department of world literature, Moscow State Pedagogical University, President of Russian Teachers of English Literature Association. Postal address: 1 Malaya Pirogovskaya St., Moscow, 119991, Russia. Tel.: +7 (499) 246-57-12. E-mail: chernozem888@yandex.ru 